\title{
Sobre mulheres: palavras e ações
}

\author{
Maria Marta Jacob \\ Professora e mestre em Ciências da Comunicação pela Escola de Comunicações e Artes da \\ Universidade de São Paulo (ECA/USP). \\ E-mail: mmartaj@uol.com.br
}

Resumo: Esta resenha apresenta uma análise da obra Empoderadas - mulheres eternas corpo a corpo, de Palmério Dória. O livro possui um poder capital: o império das mulheres. O resultado é um texto fluido e interessante que contribui para explicar a importância do ativismo político feminino nos diferentes campos sociais. Há uma dinâmica dialógica que possibilita conhecer a interação de mulheres com os mesmos objetivos independentemente das fronteiras geográficas que as distanciam.

Palavras-chave: sociedades; mulher; ativismo; política; discurso.
Abstract: This review presents an analysis of the work Empoderadas - mulheres eternas corpo a corpo, by Palmério Dória. This book had a key power - women's empire. The result is a smooth flowing and interesting text, which contributed to explain the significance of women's political activism in different social fields. There is a dialogical dynamic that allows the reader to know the interaction of women with the same objectives regardless of the geographical borders separating them.

Keywords: societies; women; activism; politics; discourse. 
O jornalista e escritor Palmério Dória lançou, em 2018, Empoderadas: mulheres eternas, corpo a corpo com a vida ${ }^{1}$. O livro possui um poder capital: o do império das mulheres. A intenção precípua do autor ao escrevê-lo é traçar uma narrativa cujo espaço/tempo se apresenta prudentemente colmatado nos campos histórico, geográfico, literário, cultural, econômico e, principalmente, político. O resultado é uma história fluida e interessante em que os pares dialéticos singular/mundial e objetivo/subjetivo contribuem para explicar a importância do ativismo político da mulher nas diferentes sociedades.

Há uma dinâmica dialógica desses campos que se revela desafiante, no sentido de ser desbravada, conhecida, compreendida, interpretada e, muito mais, de possibilitar a interação de mulheres com os mesmos objetivos independentemente das fronteiras geográficas que as distanciam. Nesse sentido, a área semântica do feminismo se amplia e se ressignifica considerando os tempos históricos, o cotidiano, o senso comum, o real e o imaginário, formando uma espécie de rede que abarca as relações humanas.

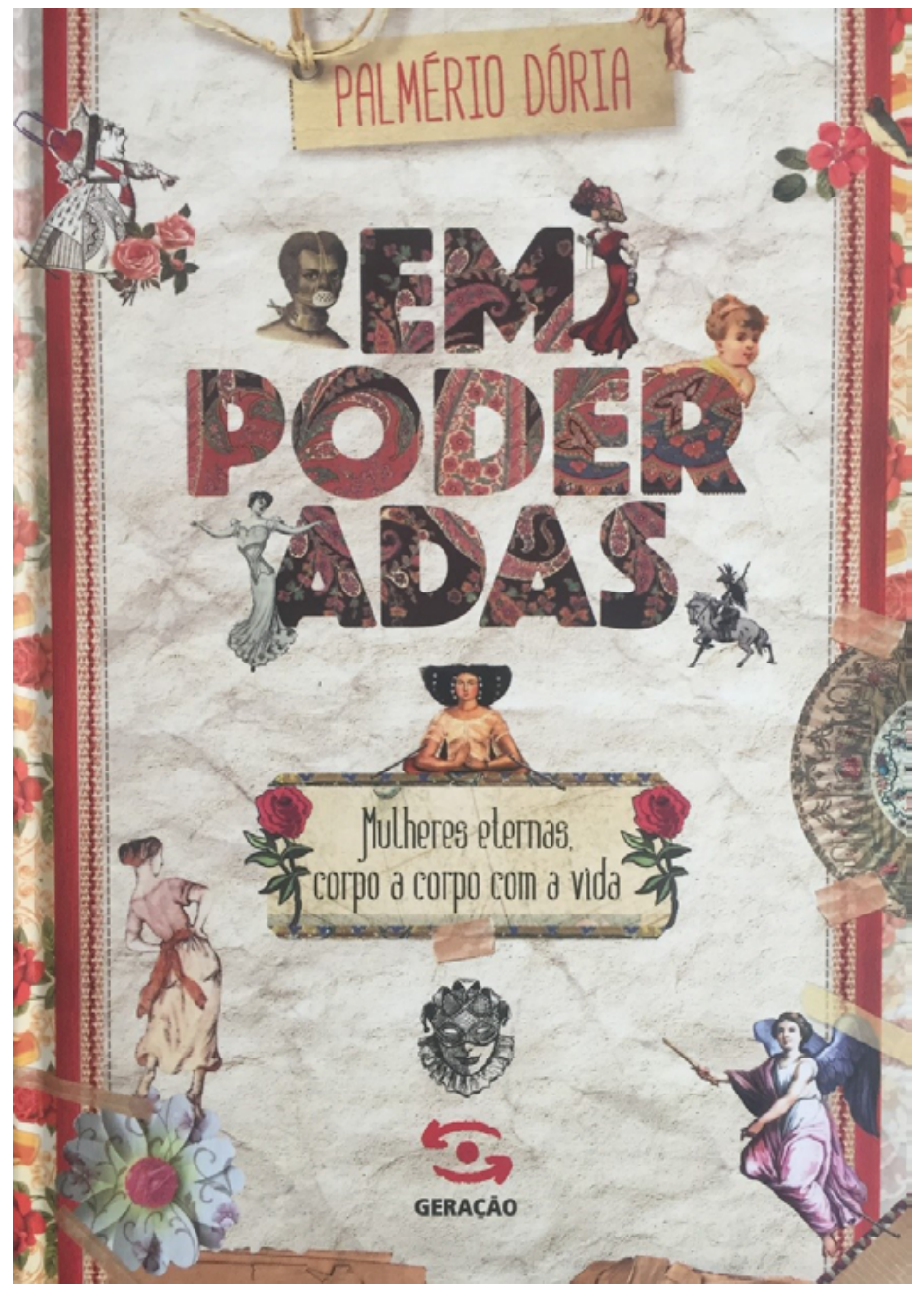

Figura 1: Palmério Dória e Alan Maia constroem uma obra com informação e arte: Empoderadas: mulheres eternas, corpo a corpo com a vida

1. DÓRIA, Palmério. Empoderadas: mulheres eternas, corpo a corpo com a vida. São Paulo: Geração Editorial, 2018. 
O projeto gráfico e a diagramação, desenvolvidos por Alan Maia (Figura 1), seguem o propósito da narrativa. A criação artística se entrelaça com a estética feminina e com os posicionamentos adotados pelo autor para configurar esse universo tão discutido nas relações interpessoais. Peças do vestuário feminino, rendas, retratos, ilustrações mitológicas, religiosas, flores, capas de revistas, fotos de jornais, cartazes, reclames, carros e posts desfilam nas páginas para complementar o sentido temático e dialogar com o texto e o leitor.

Todo esse trabalho textual e ilustrativo se concretiza e se legitima com a inserção de um fragmento da Declaração dos Direitos Humanos nas páginas iniciais, o que instiga a leitura do livro.

Em 1789, a Assembleia Constituinte proclamou na Declaração dos Direitos do Homem que todos os homens nascem livres e se mantêm iguais em seus direitos - todavia, o documento não compreendia o status dos judeus, nem dos escravos nas colônias, nem das mulheres em qualquer lugar².

Nessa perspectiva de narrativa histórica, Palmério divide o texto em capítulos, o que imprime mais facilidade à leitura, pluralidade de informação e de conhecimento, além de conferir um caráter polifônico à construção dos discursos das mulheres no cotidiano histórico.

No prefácio, o jornalista apropria-se de um fato que envolve Francisco de Orellana e frei Gaspar Carvajal - cronista de uma expedição do fim de 1539. O autor apresenta o momento em que os expedicionários aportam em uma tribo indígena só de mulheres, as icamiabas - "mulheres sem marido", na língua dos índios. A partir daí, desperta no leitor uma vontade dilacerante de mergulhar no nível incomensurável da cultura indígena, da religião, da geografia... Mas nenhum desses mergulhos se encerra em si mesmo: há uma preocupação em identificar a relação passado/presente no que tange ao tratamento dado às índias mulheres e à luta que elas ensejam para garantir o cumprimento de direitos nos conflitos políticos.

Das índias nas cercanias do Rio Nhamundá à guerreira Joana D’Arc, na França, retrata casos de cerimônias sagradas, de produção de amuletos da sorte, de bruxaria, entre outros, para compor o quadro das condições de vida das mulheres num processo paradoxal, em que muitas vezes "vozes, masculinidade e virgindade eram apenas cortina de fumaça. A questão era eminentemente política"’. A comandante militar francesa Joana D’Arc acabou virando apenas mais uma vítima da Guerra dos Cem Anos e do patriarcalismo dominante. Quatro séculos depois, canonizada pelo papa Bento XV, tornou-se a padroeira da França. Há outras menções feministas que também ganham relevância no prefácio: o posicionamento de Simone de Beauvoir; o conteúdo do Relatório Kinsey, do biólogo Alfred Kinsey; e referências religiosas a Eva e Adão, a Clara de Assis, a Rita de Cássia e à Virgem Maria.

Todos esses indicativos evidenciam a perspicácia e a capacidade de observação do autor, com o uso de um discurso lastreado na informação, na história, na argumentação, e lançando mão de recursos linguísticos como ironia, 
metáfora, entre outros. A aproximação e a integração entre os gêneros literários ultrapassam as possibilidades de detalhamento do tema em questão. Há em todos os textos uma coerência e uma coesão que permitem a interpretação histórico-política e religiosa eximida de qualquer fragmentação discursiva.

O horizonte delineado nessa perspectiva coloca as empoderadas daquela época numa posição que incomoda e surpreende as sociedades, como forma de agressão ao status quo. Nos capítulos subsequentes, o jornalista utiliza-se de um recurso significativo para configurar sua narrativa analítica sobre o feminismo: faz dois recortes, um referente aos anos 1900-1990, e o outro a partir de 2000. No primeiro recorte, relativo ao ano de 1900, Dória elege figuras femininas emblemáticas. "Ó abre alas" é o mote para a apresentação de uma delas, a compositora, pianista e maestrina Chiquinha Gonzaga.

Em qualquer época dos seus trepidantes 87 anos, entre o Segundo Reinado escravocrata e a República Velha da tardia belle époque, nostálgica da escravidão, a compositora, pianista e maestrina Chiquinha Gonzaga (1847-1935) estava fazendo uma revolução ${ }^{4}$.

O preparo social e histórico desse fragmento fornece uma dimensão significante de Chiquinha, à frente de seu tempo e com aspectos que abalavam os alicerces da "sagrada família". A presença dessa realidade revolucionária contribui para o recurso intertextual usado pelo jornalista ao ressaltar o romancista Machado de Assis. Para ele, a Capitu de Machado, em Dom Casmurro, emerge como namoradinha do Brasil: "Os olhos de ressaca de Capitu estão em alta até hoje" . O livro, publicado no contexto do Realismo, ressoa na atualidade como forma de reflexão sobre mulheres hábeis, sinuosas, que procuram alcançar seus fins por meio de estratégias de enfrentamento de oposições ideológicas e políticas.

Aos chegar no ano de 1910, Dória parafraseia a interjeição "Ave, Palavra!", da obra homônima de Guimarães $\operatorname{Rosa}^{6}$, para referir-se à trajetória da anarcossindicalista Juana Rouco Buela, oradora feminista internacional. Observa-se, neste momento, o poder da linguagem verbal e dos discursos como lugar de interpelação, de negociação e de denúncia em época de repressão, nos idos de 1917. Faixas, bandeiras, folhetos, textos publicados em revistas e livros compõem a esfera do processo heterogêneo de vozes ideológicas no papel decisivo de romper com as injustiças sociais e econômicas, sem cair no discurso panfletário, em meio à truculência policial. Nesse sentido, o campo semântico amplia-se e favorece a reflexão sobre ações humanas relacionadas ao direito das mulheres. Mesmo com esse teor anarquista e revolucionário, a narrativa adquire leveza nas analogias com o campo da moda, do cinema, da música e das "boas pinceladas" da dupla Leolinda Daltro e Bertha Lutz.

Já o capítulo "Planeta Pagu" exalta a escritora Patrícia Galvão (Pagu), que se empenhou nas chamadas "causas identitárias, que hoje florescem no planeta, nas grandes batalhas políticas"7. Há um relato turístico sobre essa intelectual feminina que se enquadra na realidade brasileira como protagonista na luta contra os preconceitos sociais. Aqui se destacam, também, Tarsila do Amaral,

4. Ibidem, s./p.

5. Ibidem

6. ROSA, João Guimarães. Ave, palavra. São Paulo: José Olympio, 1970

7. Ibidem, s./p. 
Anita Malfatti, outros nomes da literatura e das artes, além da cantora e dançarina Louise Smith e de Josephine Baker.

Nessa linha, como "Modelo revolucionária", surge a ítalo-americana Tina Modotti - operária têxtil, atriz de teatro popular, fotógrafa e femme fatale do cinema mudo na Hollywood nos anos 1920. Apropriando-se de uma diagramação sustentada por posts, fotos e ilustrações diversas nos textos biográficos, literários e históricos, o autor elenca figuras de ativistas como Olga Benário, Eros Volúsia, Cecília Meireles, Carlota Queirós, Bidu Sayão, Carmen Miranda, Gilka Machado, Maria Bonita e Djanira, cada uma com suas particularidades discursivas, que envolvem o individual e o social num movimento contínuo sustentado pela palavra e pela linguagem para manter suas concepções, ideias e interlocuções.

Quanto à década de 1940, há um “desfile” de atrizes femininas, e Dória lhes atribui autoestima maior, como se as transformasse em atrizes da própria vida e da vida de toda a sociedade, o que vai "Muito além da realidade". A médica alagoana Nise da Silveira ganha destaque com as características de mulher criativa e visionária. Dória reproduz uma declaração da ativista sobre si mesma:

"Não se cura além da conta. Gente curada demais é gente chata. Todo o mundo tem um pouco de loucura. Vou lhes fazer um pedido, vivam a imaginação, pois ela é a nossa realidade mais profunda. Felizmente, eu nunca convivi com pessoas muito ajuizadas"

Além da médica, existem também mulheres valentes aviadoras da União Soviética que participaram da Segunda Guerra. Para fechar esse cenário de 1940, o jornalista aponta dona Leocádia (mãe de Carlos Prestes), Clarice Lispector, Lina Bo Bardi e, na música, Marlene, Emilinha etc.

Mas é nos anos 1950, no "Samba-canção do amor demais", que se vislumbra Dolores Duran, cantora e compositora que exerceu papel preponderante na música. A homenagem do autor é a construção de um texto mesclado de informações e versos poéticos de letras de músicas que exaltam o amor, como em "O negócio é amar": “Tem gente que ama, que vive brigando/ E depois que briga acaba voltando..., letra musicada por Carlinhos Lyra”.

Esse texto informativo-poético ganha, em alguns momentos, um efeito humorístico construído por Palmério numa esfera subjetiva, que envolve valores éticos em atitudes que confrontavam o conservadorismo e as vicissitudes da época. Navegam, no rádio, Dalva e Elizeth Cardoso; no teatro, Virgínia Lane; nas letras, a escritora norte-americana Elizabeth Bishop; como também Vanja Orico entoando "Mulher rendeira", Bibi Ferreira explodindo nos palcos, Martha Rocha no pódio da beleza; e o rádio ainda presente com a voz de Ângela Maria; além da televisão e dos jornais divulgando Maria Esther Bueno, Maysa e Elizeth.

$\mathrm{O}$ alcance artístico do autor, ao enunciar um planejamento cronológico artistico, legitina o uso da palavra em ação, em movinento, na função ambigua, na construção de um elo mais efetivo entre o escritor e o leitor para apresentar essa galeria de mulheres fortes na sociedade mundial. 


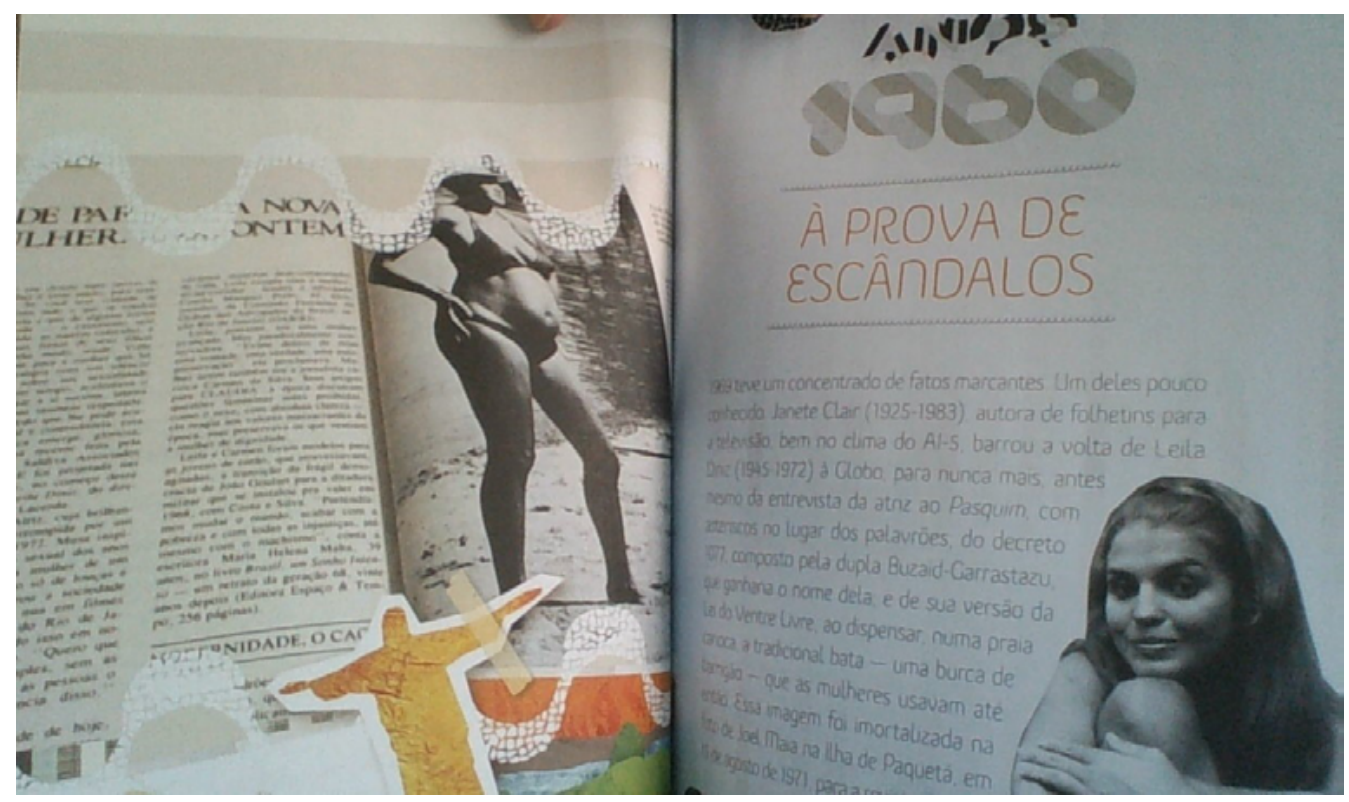

Figura 2: Leila Diniz enfrenta os poderosos: a emancipação do corpo feminino

Em "À prova de escândalos", põem-se à vista desdobramentos da sobrevivência de Leila Diniz a episódios divulgados na mídia, com ecos na política relativos a família, censura e golpe. Dário não se exaure na análise do caso de Diniz e, nessa perspectiva, os aspectos de rebeldia e coragem se estendem em Rita Lee, Valentina Tereshkova e Luz Del Fuego; enquanto, no ano de 1967, a sociedade convive com a perseguição de educadoras do Rio de Janeiro e de São Paulo, em razão dos discursos sobre sexo nas escolas, e com a denúncia de Ligia Doutel sobre um projeto ambiental. Esses fatos são enunciados em posts com textos curtos e informativos, e há uma preocupação em alertar o leitor sobre problemas que se perpetuam na maioria das sociedades, mas são combatidos por mulheres audaciosas e comprometidas com a causa política. No mesmo percurso linguístico, outras figuras se destacam, como Thereza Goulart, Carmen da Silva, Maura Cançado, Elis Regina, Niomar Sodré e Hilda Hilst, a fim de construir mais uma página informativa.

Valendo-se da sequência factual e histórica, o jornalista expõe mais um contundente retrato social: “Os anos de 1970”. As páginas dedicadas a esse período trazem, novamente, textos curtos, em linguagem objetiva e com alternância de vozes do próprio autor, para argumentar, narrar, informar e corroborar o ambíguo quadro sociopolítico em época de ditadura. Mulheres guerrilheiras, fortes, batalhadoras e ativistas assumem novamente o protagonismo na narrativa. Desfilam, aqui, Dina da Conceição, Rachel de Queiroz, Zuzu Angel, Arethuza Silva, Lucélia Santos, Mãe Menininha, Jane Fonda, Katharine Graham, Inês Romeu, entre outras.

A reportagem inspiradora de Carlos Azevedo, na revista Doçura, sobre o assassinato da empresária mineira Eloísa Ballesteros é o mote do capítulo "Fera ferida”, referente ao momento político da década de 1980. O jornalista intenta catalisar a percepção da eclosão dos diferentes temperamentos masculinos nos casos de feminicídio. Faz veemente crítica ao fato de a revista Doçura não ter 
circulado em Minas por nepotismo. Após dar ênfase ao feminicídio, volta-se para a música, com Cláudya; para a TV, com Rose Nogueira e Marta Suplicy; e para a política, com Luiza Erundina, que surpreendentemente derrota, em seu percurso ativista, o malufismo, o quercismo e o janismo. Ademais, a índia caiapó Tuíra rouba a cena na narrativa: Dória encerra o capítulo relatando o inegável valor histórico dessa mulher, cuja ação desencadeou o 1ำ Encontro dos Povos Indígenas do Xingu e, consequentemente, reforçou a luta desse povo pela legitimidade de seu direito sobre a terra. Destaca-se também Joênia Wapichana, a primeira brasileira de origem indígena formada em direito a exercer a profissão.

Então surgem, nesse discurso empoderado feminino, "Os anos 1990". Com textos um pouco mais densos, mas com leveza da linguagem, emerge a narrativa histórica sobre Getúlio Vargas. O autor denuncia a participação significativa de Alzira Vargas como atriz na cena política. Num relato subsequente, na mesma linha analítico-histórica, revela-se Rigoberta Menchú, índia guatemalteca, veterana na luta pelos direitos humanos. Marina Silva, Marisa Monte, Gisele Bündchen e Fernanda Montenegro também são inseridas nesse espaço com apreço e cuidados que encantam leitores com diferentes visões.

A frase "A paz invadiu o coração de Zilda Arns" indica o início do segundo recorte da análise sobre a mulher no livro de Palmério Dória, a partir do ano 2000. As reflexões feitas até aqui reforçam o êxito das ações femininas nas sociedades, o que significa dizer que há um olhar em direção ao presente na perspectiva de interiorização dos conflitos sociais que envolvem políticas públicas embasadas na dialética subjetividade/objetividade.

Entre 2000 e 2018, o jornalista ratifica o teor biográfico-histórico do texto. Há um recurso parafrástico com o objetivo de manter um sentido temático comum nos vários campos explorados, mas existe também uma preocupação com a indicação de um novo sentido, em um processo polissêmico, visando ao encadeamento das estratégias de ativistas - como as de Zilda Arns nas práticas solidárias, a garra da jogadora Marta, o enfrentamento da violência contra a mulher por Maria da Penha, o heroísmo da baiana Anna Nery, a militância da argentina Estela de Carlotto, a performance da atriz e professora Maria Alice Vergueiro no YouTube, bem como a atuação de Ausonia Donato nas áreas da saúde e da educação.

$\mathrm{O}$ autor dedica um espaço relevante, também no ritmo polissêmico e parafrástico, para discorrer sobre a ex-presidente Dilma Rousseff. Percebe-se, nesse momento, um encadeamento verbal que prioriza a participação significativa na política e no processo democrático dessa ativista. Dória acentua toda a representação da figura feminina em dissonância com o descaso das autoridades em relação aos direitos garantidos pela Constituição e a oportunidade de o povo brasileiro conhecer a trajetória da primeira mulher presidente do Brasil.

A ganhadora do Nobel da Paz em 1972, a liberiana Leymah Gbowee, e a rainha do Ndongo e do Matamba, Njinga a Mbande, também recebem, do escritor, destaque pela participação política em suas respectivas sociedades. 


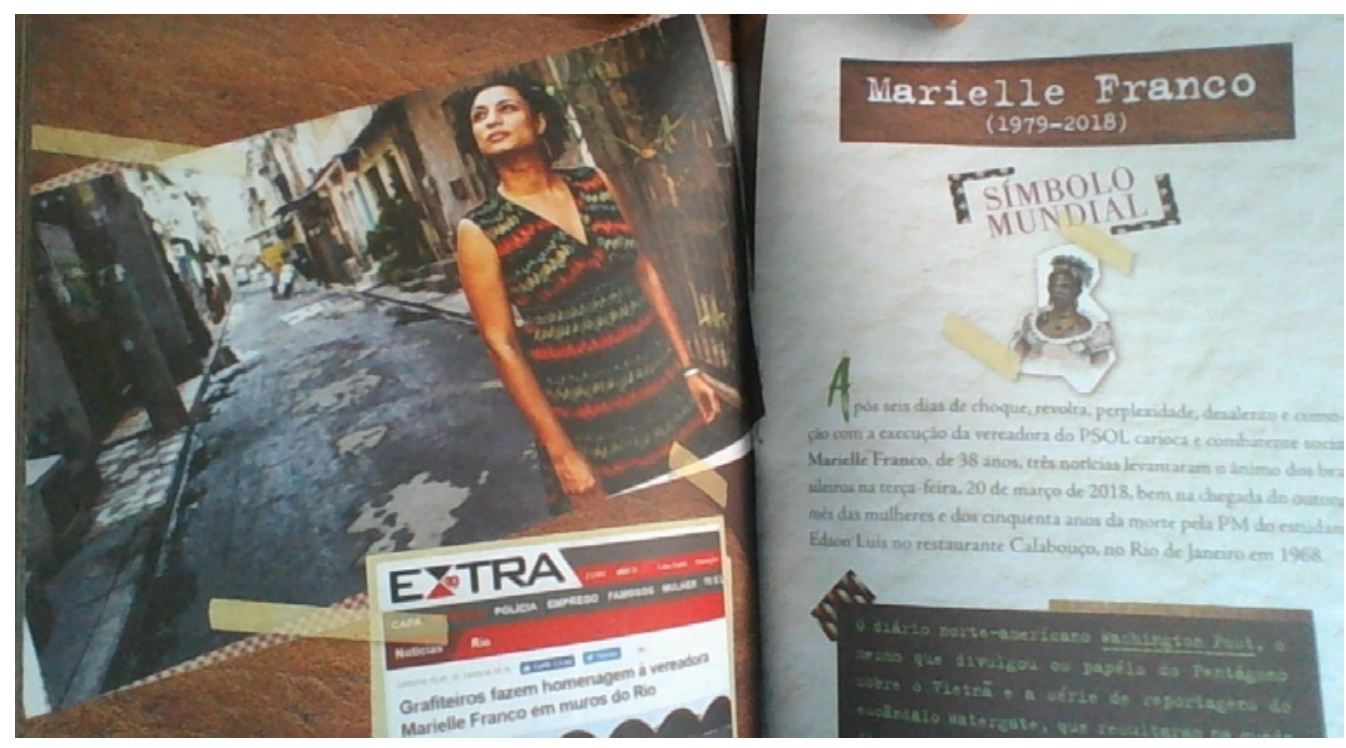

Figura 3: Marielle Franco: o assassinato do corpo não mata as ideias, outras mulheres virão por elas

Ao longo das enunciações, Palmério demonstra maestria analítica, o que garante a continuidade da leitura, estando sempre preocupado em manter a interação com o leitor e o tom crítico. A escolha léxico-semântica revela o sentido de indignação e de exaltação da força feminina no âmbito socioeconômico.

Em relação a fatos mais recentes, há novos posts para destacar Amy Winehouse, Clara Charf, a ocupação das escolas paranaenses, a morte da heroína russa Major Nadezhda, o prêmio da fotógrafa Elvira Alegre, o bicentenário de Karl Marx e a atuação de sua filha e ativista Eleanor Marx, a morte da americana Naomi Parker, ícone das trabalhadoras durante a 2ª Guerra Mundial, a ativista transexual brasileira Linn da Quebrada, as atletas Jacqueline Silva e Sandra Pires, a ativista Sandra Davis, o episódio de racismo de William Waack e a consequente revolta das mulheres, principalmente, e a reação de Madonna quanto à vitória de Trump.

No capítulo final, Marielle Franco desponta como símbolo global.

Marielle era negra, pobre, favelada. Neta de um retirante da Paraíba, gostava de se dizer cria da Maré. Foi ali, no bairro com a segunda maior taxa de analfabetismo do Rio, que ela começou a lutar para não virar esteticista ${ }^{10}$.

A ativista lutava veementemente contra as injustiças, a desigualdade e as ações veladas do poder público sobre a manutenção do status quo. Dória destaca a participação significativa da socióloga de 38 anos na política brasileira, e há no texto uma argumentação segura, com pormenores realistas e o histórico da condição dos negros em âmbito nacional. O autor acrescenta a opinião de outros jornalistas, de Frei Betto, da Conferência Nacional dos Bispos do Brasil (CNBB) e, para finalizar o livro, versos do poema "Memória", de Carlos Drummond de Andrade: "As coisas findas,/ muito mais que lindas,/ essas ficarão"11.

Das índias icamiabas a Marielle, revelam-se perfis que configuram a possibilidade da erradicação dos problemas referentes às mulheres na arena 
sócio-histórica do Brasil e do mundo. Palmério Dória e Alan Maia, em um percurso verbal e estético, conseguem mostrar ao leitor o romantismo e a essência do trabalho das ativistas, num esquema que desemboca na realização de lutas sociais. O incisivo poder das palavras, no livro, revela-se por meio da informação, da poesia, da notícia jornalística, da argumentação e de vários gêneros discursivos, com a capacidade de construção de sentidos tais que podem mascarar a realidade, mas também denunciar e revelar as vicissitudes sociais.

Empoderadas é um livro para ser lido e tornar reconhecíveis as armadilhas históricas que podem ser combatidas.

\section{REFERÊNCIAS BIBLIOGRÁFICAS}

DÓRIA, Palmério. Empoderadas: mulheres eternas, corpo a corpo com a vida. São Paulo: Geração Editorial, 2018.

BACCEGA, Maria Aparecida. Da palavra ao discurso: história e literatura. São Paulo: Ática, 1995.

BRANDÃO, Helena Nagamine. Introdução à análise do discurso. Campinas: Unicamp, 1991.

JACOB, Maria Marta. Infância na arena das palavras. Dissertação de Mestrado. São Paulo: ECA-USP, 2002.

ORLANDI, Eni. Análise de discurso: princípios e procedimentos. Campinas: Pontes, 1999.

ROSA, João Guimarães. Ave, palavra. São Paulo: José Olympio, 1970. 